Article

\title{
Antioxidant and Potentially Anti-Inflammatory Properties in Pasta Fortified with Onion Skin
}

\author{
Monika Michalak-Majewska ${ }^{1}{ }^{\mathbb{D}}$, Urszula Złotek ${ }^{2, *}{ }^{\mathbb{D}}$, Urszula Szymanowska ${ }^{2}$, \\ Dominik Szwajgier ${ }^{3}$, Piotr Stanikowski ${ }^{1}{ }^{\mathbb{D}}$, Małgorzata Matysek ${ }^{4}$ and Aldona Sobota ${ }^{5}$ \\ 1 Department of Fruits, Vegetables and Mushrooms Technology, \\ Department of Plant Food Technology and Gastronomy, University of Life Sciences, Skromna Str. 8, \\ 20-704 Lublin, Poland; monika.michalak@up.lublin.pl (M.M.-M.); piotr.stanikowski@up.lublin.pl (P.S.) \\ 2 Department of Biochemistry and Food Chemistry, University of Life Sciences, Skromna Str. 8, \\ 20-704 Lublin, Poland; urszula.szymanowska@up.lublin.pl \\ 3 Department of Biotechnology, Human Nutrition and Food Commodity Science, University of Life Sciences, \\ Skromna Str. 8, 20-704 Lublin, Poland; dominik.szwajgier@up.lublin.pl \\ 4 Department of Animal Anatomy and Histology, University of Life Sciences, Akademicka Str. 12, \\ 20-0330 Lublin, Poland; malgorzata.matysek@up.lublin.pl \\ 5 Division of Engineering and Cereals Technology, Department of Plant Food Technology and Gastronomy, \\ University of Life Sciences, Skromna Str. 8, 20-704 Lublin, Poland; aldona.sobota@up.lublin.pl \\ * Correspondence: urszula.zlotek@up.lublin.pl; Tel.: +48-81-4623328
}

Received: 20 October 2020; Accepted: 13 November 2020; Published: 18 November 2020

\begin{abstract}
In recent years, food industries have produced a large volume of waste, which is an ecological and economic problem. Fruit and vegetable by-products can also be promising sources of functional compounds, with documented pro-health potential. The goal of the study was to evaluate the impact of the addition of various concentrations of onion skin powder on the antioxidant and anti-inflammatory properties associated with changes in the quercetin content in uncooked and cooked pastas. The total contents of phenolic acids, quercetin, and antioxidant activity were determined. The anti-inflammatory activity was demonstrated by inhibitory effects on lipoxygenase (LOX) in vitro activity. Dry onion skin is the source of quercetin in analyzed pastas. The concentrations of these compounds gradually and significantly increased with increases in the vegetable component in fortified pastas. Additionally, a positive correlation between the content of phenolic compounds and antioxidant activity of pastas fortified with onion skin powder was noted. The process of cooking caused enhancement in the antioxidant and anti-inflammatory potential. These qualities of pastas resulted from the presence of dry onion skin with high pro-health activities. Fortification of pasta with onion skin powder could be a starting point to benefit onion industrial by-products and produce new healthy food products.
\end{abstract}

Keywords: fortified pasta; onion skin; antioxidant activity; anti-inflammatory activity; quercetin

\section{Introduction}

Onion (Allium cepa L.) is the most widely cultivated species of the genus Allium, and the second (after tomatoes) most important horticultural crop worldwide. Current annual production is about 88 million tons, and the largest producer is Asia (55 million). Less than 10 million tons of onion is produced in Europe, where Poland is the third largest producer, with a yield amounting to 660 thousand tons in 2018 [1]. A commonly used part of onion is the bulb, which is a raw material or food ingredient, because of its specific flavor and pungent smell [2]. Numerous studies have confirmed the pro-health activities of onion by in vitro and in animal model tests, in particular, antioxidant, antibacterial, antifungal, cardio-protective, anti-inflammatory, anti-carcinogenic, anti-obesity properties, 
and the promotion of glycemic control [3,4]. These features are attributed to bioactive compounds, among which phenolic compounds, including phenolic acids and flavonoids, constitute a large group (mainly quercetin diglucoside, quercetin 4 '-glucoside, quercetin aglycone, isorhamnetin monoglycoside, and kaempferol monoglycoside), phenolic acids (ferulic, p-coumaric, gallic, 3,4-dihydroxybenzoic), sulphur compounds, and non-structural carbohydrates. Concentrations of these compounds depend on cultivar, stage of ripeness, environment and agronomic conditions, storage time, and, in addition, the bulb section (inner, outer scales or dry skin) [5-7].

During the processing of onions, about 30\% of fresh material is removed and considered useless waste, which includes dry skin [8]. These wastes are an ecological and economic problem, and the main difficulty in their management is their heterogeneous character. The composition of the onion waste varies depending upon the morphological part of the bulb. Therefore, a common strategy for all of them cannot be adopted [9]. A possible solution to use dry onion skin could be to use it as a source of valuable food ingredients such as insoluble dietary fiber, minerals (especially calcium and potassium), and highly bio-accessible and in vitro bioavailable flavonoids with well-documented antioxidant and anti-inflammatory abilities [10-13].

Literature data suggests taking into account the utilization of onion skin as a valuable by-product in the food processing industry $[14,15]$, especially since the bioactive components of the flavonoid group are relatively thermally resistant. In recent years, dry onion skin has been used to design functional or enriched foods, such as pasta [16,17], noodles [18], bread [19], extruded products [20], and yoghurt [21]. In addition, the use of dry onion skin has also been considered as a raw material for the health industry for medicines and pharmaceuticals [11] and in the textile industry [22].

Studies focusing on the effects of different plant components in addition to food products suggest that among various assortments of cereal products, pasta is especially suitable as a carrier of bioactive substances. Pasta is one of the most popular convenience food in the world for its easy preparation, nutritional value, and palatability [23]. Due to the fact that fruit and vegetable by-products contain bioactive compounds with significant biological activity, they are of interest to international researchers. Over the last few years, numerous studies have considered the possibility of incorporation of by-product extracts or powders for preservation or enrichment of food products. This is associated with current interest of consumers, who are demanding the production of safer and health-promoting foods [24].

Currently, pasta is fortified with by-products such as mango peel [25], tomato skin [26], outer bracts, leaves, stems of artichoke [27], cereal brans [28], bean flour [29], olive oil industrial by-product [30], beef meat [31], and shiitake and porcini [32]. Therefore, such pasta is considered to be a "convenient food with a high pro-health potential for future generations" [23].

Our previous study indicated that onion skin powder used as substitute for wheat flour leads to changes in the technological and culinary properties of supplemented pastas. With increasing levels of onion skin, optimal cooking time and water solubility index decreased. In addition increased cooking loss and redness $\left(\mathrm{a}^{*}\right)$ were noted, compared to the pasta without skin [16]. The aim of the present study was to evaluate the impact of addition of various quantities of onion skin powder on the antioxidant and anti-inflammatory properties, as well as quercetin content, in uncooked and cooked pastas.

\section{Materials and Methods}

\subsection{Materials}

Basic materials used in the study were semolina durum (SE) (Jula Malom, Kunszállás, Hungary) and onion skin powder (OS) from the Polanowska cultivar (Czesławice Experimental Farm, Czesławice, Poland ( $\left.51^{\circ} 18^{\prime} 23^{\prime \prime} \mathrm{N}, 22^{\circ} 16^{\prime} 02^{\prime \prime} \mathrm{E}\right)$ ). To obtain the OS, onion was manually peeled, and dry material was washed twice in deionized water and dried at $50^{\circ} \mathrm{C}$ for $12 \mathrm{~h}$ in a convection dryer (Zelmer, Poland). The onion skin was powdered in a laboratory mill (Proficook, Poland) and then sieved to pass through a $0.5 \mathrm{~mm}$ mesh screen. 


\subsection{Pasta Production}

In the preparation of pasta, SE was substituted with OS at $0 \%(\mathrm{~m} / \mathrm{m})$ (control-P0), $2.5 \%(\mathrm{~m} / \mathrm{m})(\mathrm{P} 2.5)$, $5 \%(\mathrm{~m} / \mathrm{m})(\mathrm{P} 5)$, and $7.5 \%(\mathrm{~m} / \mathrm{m})(\mathrm{P} 7.5)$ proportions. Pasta was prepared on a semi-industrial scale (MAC $30 \mathrm{~S} \mathrm{Lab}$, ItalPast, Fidenza, Italy, screw speed $60 \mathrm{rev} / \mathrm{min}$, extrusion pressure $15 \mathrm{MPa}$ ). SE with the addition of OS was hydrated to reach $30 \%$ moisture, mixed in a vacuum mixer, and extruded at $40{ }^{\circ} \mathrm{C}$. Then, pasta was dried in astatic dryer (EAC $30 \mathrm{Lab}$, ItalPast, Fidenza, Italy) at $35-55^{\circ} \mathrm{C}$ and a humidity level of $85-55 \%$. Dried pasta (100 g) was cooked in $1000 \mathrm{~mL}$ of boiling distilled water. After cooking, the pasta was cooled at room temperature, and then frozen and lyophilized in a laboratory freeze drier (Alpha 1-2 LD plus; Martin Christ, Osterode am Harz, Germany). The freeze-dried pasta was ground and sieved through a $0.25 \mathrm{~mm}$ sieve. The samples were stored in the dark at $-20^{\circ} \mathrm{C}$.

\subsection{Preparation of Extracts}

For the preparation of ethanolic extracts, powdered samples of pasta (P0-P7.5) (2 g), SE (2 g), and OS $(1 \mathrm{~g})$ were extracted for $1 \mathrm{~h}$ with $20 \mathrm{~mL}$ of $50 \%(v / v)$ ethanol and centrifuged $(9000 \times g$ for $20 \mathrm{~min}$.); then the extraction procedure was repeated. The supernatants were combined and adjusted to the final volume of $50 \mathrm{~mL}$ with $50 \%$ (v/v—ethanol/water) ethanol [33].

\subsection{Determination of Phenolic Acid Content (PAC)}

The total content of phenolic acids was determined according to the Arnov method [34] and expressed as caffeic acid equivalent (CAE) in $\mu \mathrm{g}$ per g of dry weight (DW).

\subsection{HPLC Analysis}

HPLC analyses of onion extracts were conducted using a Knauer HPLC system consisting of two Smartline 100 pumps, a dynamic mixer, and a $0.02 \mathrm{~mL}$ loop. For separations, a Macherey-Nagel LiChospher $100 \mathrm{RP} 18(250 \mathrm{~mm} \times 4.0 \mathrm{~mm}, 5 \mu \mathrm{m})$ column coupled with a corresponding pre-column was used. The flow was $1 \mathrm{~mL} / \mathrm{min}$ at working pressure not exceeding $28 \mathrm{MPa}$. The optimized gradient was formed by deionized water containing $0.1 \%(v / v)$ high purity formic acid (Sigma Aldrich) (A) and $70 \%(v / v)$ MS-grade methanol in deionized water with $0.1 \%(v / v)$ formic acid (B): $0-5 \mathrm{~min} 5 \%$ $(v / v)$ B, 5-40 min $5 \rightarrow 100 \%$ B, 40-45 min 100\% B, 45-48 min 100 $\rightarrow 5 \%(v / v)$ B, 48-53 min 5\% (v/v) B. Detection was performed at $365 \mathrm{~nm}$ using a Knauer Azura UVD 2.1S detector coupled with a Knauer IF2 interface. Signals were analyzed using the Eurochrom 3.05 P5 program. Quantification of the quercetin and quercetin glucosides were determined by a previously mentioned method [35]. Standard compounds such as quercetin, quercetin 3,4'-diglucoside, quercetin $4^{\prime}$-glucoside, and quercetin 3-glucoside were purchased from Sigma Aldrich. The content of each compound was expressed in $\mathrm{mg} / \mathrm{g}$ of dry weight (DW).

\subsection{Antioxidant Activities}

The free radical-scavenging activity was measured using ABTS (2,2'-azino-bis(3-ethylbenzothiazoline-6-sulphonic acid) as the source of free radicals, according to a previously described method [36]. The antioxidant activity was related to Trolox (an analogue of vitamin E) and expressed as mg of Trolox per g of dry weight (DW).

Iron-chelating activity (CHP) and ferric-reducing antioxidant power (RP) were determined according to previously described methods [37,38]. Chelating power was expressed as EDTA equivalent in mg EDTA per $\mathrm{g}$ of dry weight (DW) and reducing power as mg of Trolox per $\mathrm{g}$ of dry weight (DW).

\subsection{Inhibition of Lipoxygenase (LOX) Activity}

The ability to inhibit lipoxygenase (LOX) was determined by means of a previously described method [39], adapted to a microplate reader. LOX inhibitory activity was determined as IC50 —an 
extract concentration $(\mathrm{mg} \mathrm{DW} / \mathrm{mL})$ providing $50 \%$ of activity, based on a dose-dependent mode of action.

\subsection{Statistical Analysis}

The experimental results were presented as mean \pm standard deviation (SD). The experiments were conducted three times, and all determinations were performed in triplicate $(n=9)$. Data were subjected to one-way analysis of variance (ANOVA), and significance differences were evaluated by Tukey's comparison test $(p<0.05)$. To identify relationships between phenolic compound content and antioxidant and anti-inflammatory activities of pastas fortified with onion skin powder, data were also evaluated using Pearson's correlation coefficients. Statistica 10 software (Stat-Soft, Cracow, Poland) was used to statistical analyses.

\section{Results and Discussion}

\subsection{Phenolic Compound Content}

Onion is known for being one of the natural sources of phenolic compounds in the human diet, containing at least 25 different flavonoids. The most abundant are quercetin 3,4-diglucoside, isorhamnetin 3,4-diglucoside, quercetin 3-glucoside, quercetin 4-glucoside, quercetin aglycone, and phenolic acids, for example, ferulic, gallic, and protocatechuic acids [40]. In Allium cepa, about $90 \%$ of the quercetin is located in the first and second layers of a bulb, which are treated as waste and generated during industrial and domestic peeling. Over half of the total content of quercetin from dry onion skin is present in potentially bioavailable aglycones [12,13]. Therefore, it is worth using this source of valuable plant secondary metabolites, e.g., for pasta enrichment.

As shown in Figure 1, all uncooked pastas fortified with onion skin powder (P2.5-P7.5) were characterized by relatively similar contents of total phenolics acids (PAC), statistically not significantly higher than the control sample (P0). Neither quercetin (Q) nor any other quercetin glucosides were detectable in that last sample (P0). However, in the case of pasta after cooking with the increase of OS, concentration of PAC and Q gradually and statistically significantly increased. From among the quercetin glucosides, only quercetin-4-glucoside was identified. According to the literature, this compound is predominant among all the glycosides occurring in dry onion skins [12]. The amount of those phenolic compounds was the highest in pastas fortified with 5 and $7.5 \%(\mathrm{~m} / \mathrm{m})$ of onion skin (P5 and P7.5). In these fortified pastas, the main source of quercetin, quercetin $4^{\prime}$-glucoside and phenolic acids, was dry onion skin, because semolina (flour), which is the basic ingredient of pasta, contained a significantly lower quantity of PAC and no quercetin levels (Table 1). Semolina is perfect for making pasta due to its unique characteristics—relatively high yellow pigment content, low lipoxygenase activity, and high gluten content, which makes it possible to obtain a strong and elastic dough [41]. Studies confirm that semolina is a poor source of phenolic compounds. Its concentration in semolina is approximately one third of that in bran [42]. A group of phenolic acids is represented by $p$-hydroxybenzoic and ferulic acids [43].

The process of cooking resulted in a statistically significant increase in the content of phenolic acids content (PAC), quercetin $(\mathrm{Q})$, and quercetin $4^{\prime}$-gluciside $\left(\mathrm{Q} 4^{\prime} \mathrm{G}\right)$ in the samples of all fortified pastas to $4.52 \mu \mathrm{g} / \mathrm{g} \mathrm{DW}, 0.50 \mathrm{mg} / \mathrm{g}$ DW, and $0.06 \mathrm{mg} / \mathrm{g} \mathrm{DW}$, respectively (Figure 1). No other quercetin glucosides (quercetin 3,4'-diglucoside and quercetin 3-glucoside) were found in the extracts analyzed. A similar effect concerning the increase in the content of phenolic compounds was observed in the studies carried out on pastas fortified with phenolic-abundant ingredients, such as onion skin or fleshy husk powder [16,17,44], buckwheat [45], chia [46], linseed [47], artichoke [27], and olive oil industrial by-product [30].

It has already been proven that plant material processing can change the structure of the food matrix and may also affect either positively or negatively the plant secondary metabolites. Previous studies have demonstrated that onion flavonoids are relatively heat-stable, and onion outer scale remains the 
most abundant in flavonoids, even after cooking $[15,48]$. Probably for this reason, all fortified pastas after cooking did not have lower contents of phenolic compounds than those that were uncooked. Additionally, thermal treatment may damage the cell walls, making compounds more accessible to absorption. Results obtained in the present manuscript correspond perfectly with the research conducted by Sharma et al. [48], with regard to the observation that the total phenolic content was significantly increased after heating the onion samples to $100^{\circ} \mathrm{C}$. In addition, their results indicate that phenolic compounds from powdered onion are released by hydrolysis of the ester or the glycosidic bond. Furthermore, the formation of novel compounds as a result of the Maillard reaction contributes to the increase in the content of phenolic compounds after onion heating. These reactions are also attributed to the responsibility for higher phenolic content in buckwheat tagliatelle and durum wheat pasta enriched with debranning fractions of wheat after cooking [48].

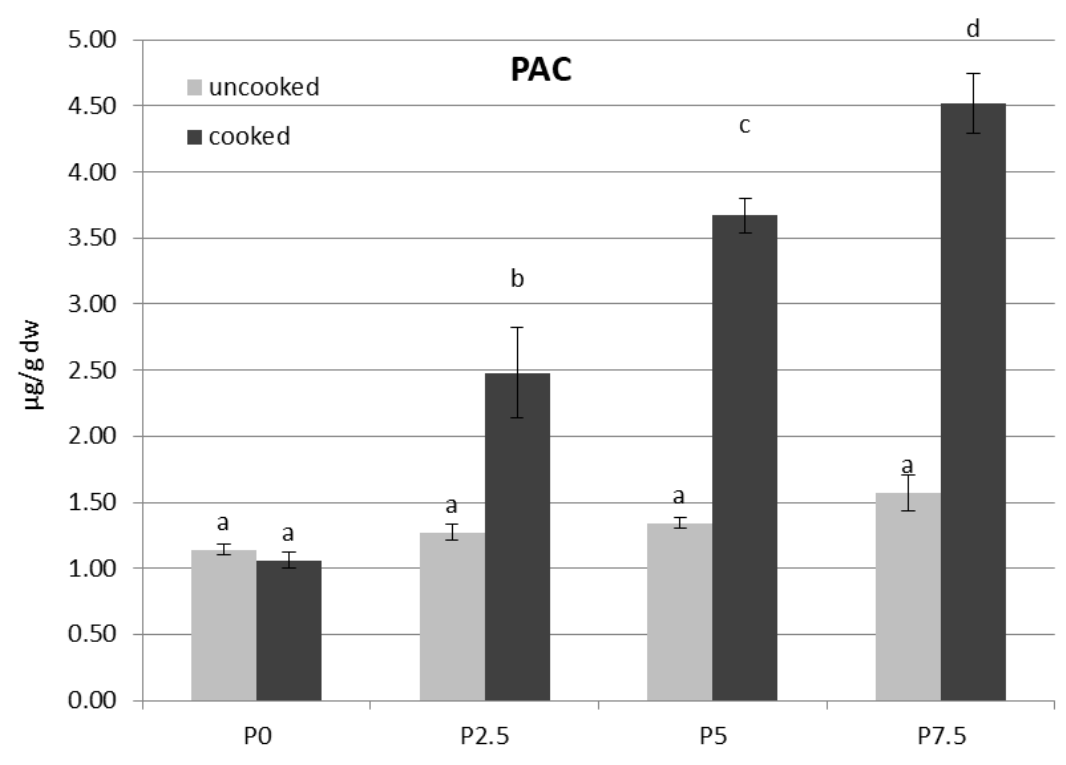

(a)

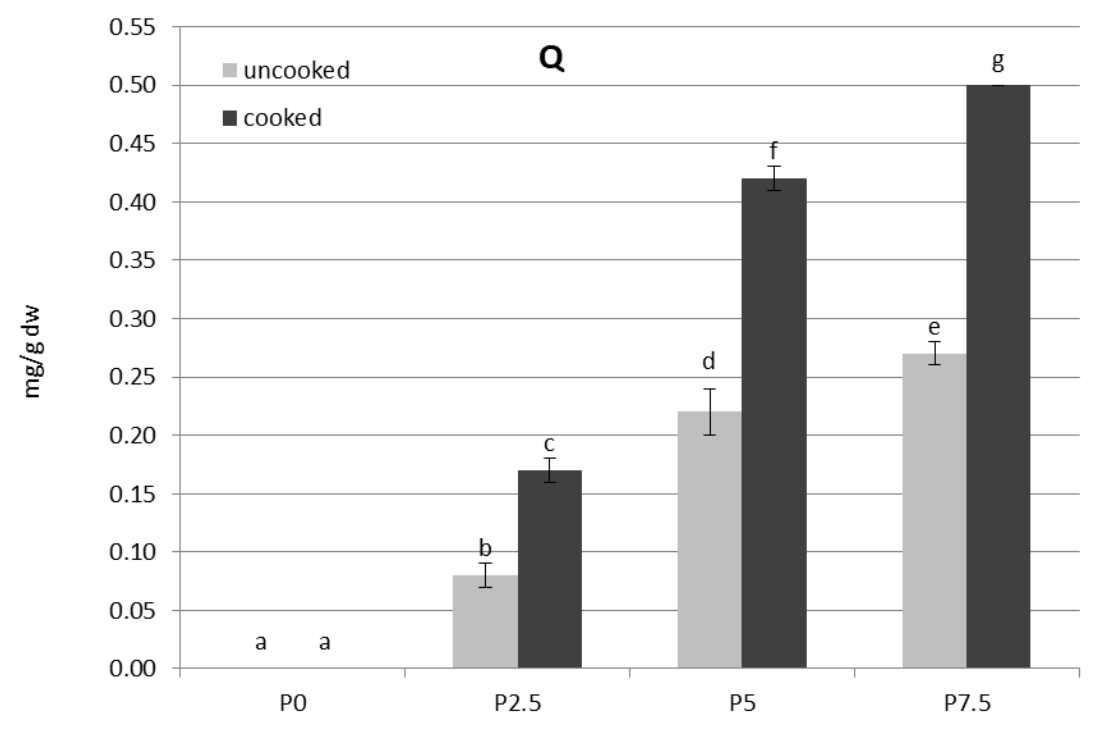

(b)

Figure 1. Cont. 


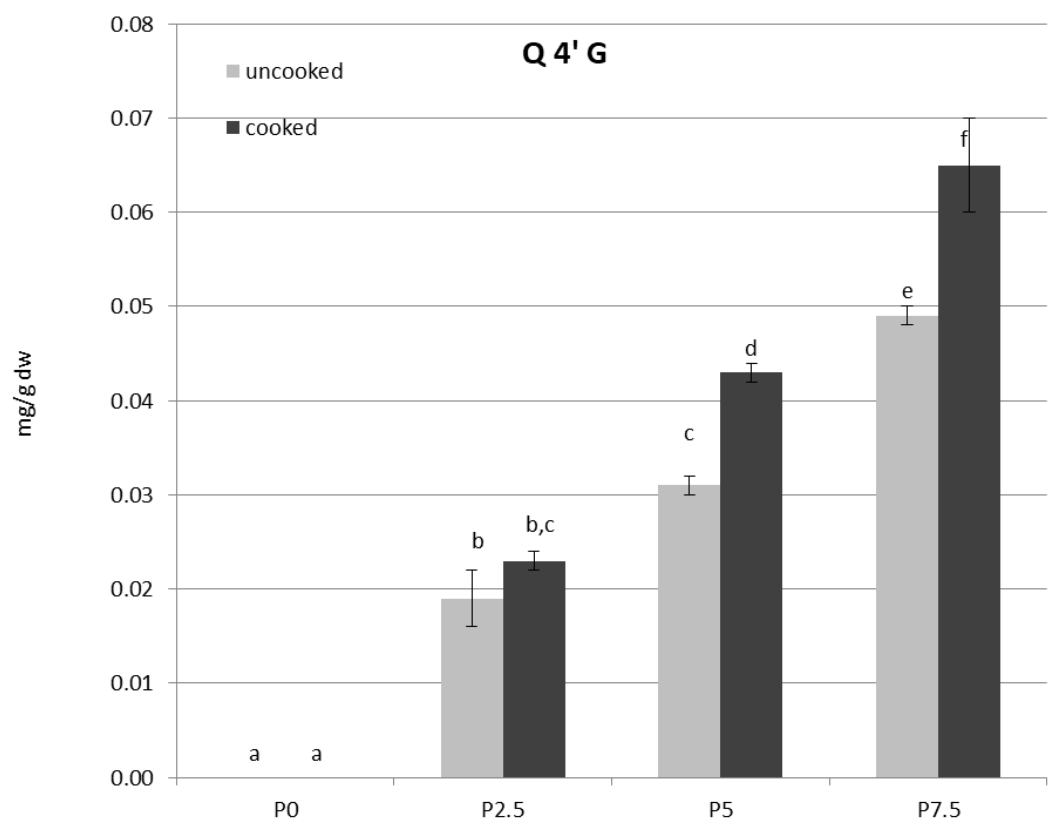

(c)

Figure 1. Comparison of total phenolic acid (PAC) (a), quercetin $(Q)(b)$, and quercetin $4^{\prime}$-gluciside content ( $\left.\mathrm{Q} 4^{\prime} \mathrm{G}\right)$ (c) of uncooked and cooked pastas fortified with onion skin powder. P0-control pasta; P2.5-7.5 pastas fortified with $2.5-7.5 \%(\mathrm{~m} / \mathrm{m})$ of onion skin powder. Different letters indicate significant difference $(p<0.05)$.

Table 1. Characteristics of raw materials used in the production of fortified pastas.

\begin{tabular}{|c|c|c|}
\hline \multirow{2}{*}{ Compounds } & \multicolumn{2}{|c|}{ Raw Pasta Materials } \\
\hline & SE & OS \\
\hline $\mathrm{PAC}(\mu \mathrm{g} / \mathrm{g} \mathrm{DW})$ & $2.74 \pm 0.46^{\mathrm{a}}$ & $28.65 \pm 3.14^{b}$ \\
\hline $\mathrm{Q}(\mathrm{mg} / \mathrm{g} \mathrm{DW})$ & $0.00 \pm 0.00^{\mathrm{a}}$ & $18.74 \pm 0.14^{\mathrm{b}}$ \\
\hline Q 4' G (mg/g DW) & $0.00 \pm 0.00^{\mathrm{a}}$ & $4.99 \pm 0.18^{b}$ \\
\hline Antioxidant activity & SE & OS \\
\hline ABTS $^{+\cdot}$ (mg Trolox/g DW) & $0.09 \pm 0.03^{\mathrm{a}}$ & $4.10 \pm 0.93^{b}$ \\
\hline RP (mg Trolox/g DW) & $2.36 \pm 0.65^{\mathrm{a}}$ & $9.08 \pm 0.69^{b}$ \\
\hline CHP (mg EDTA/g DW) & $0.08 \pm 0.02^{\mathrm{a}}$ & $1.01 \pm 0.01^{b}$ \\
\hline Anti-inflammatory activity & SE & OS \\
\hline LOX inhibition (IC50 mg DW/mL) & $0.2759 \pm 0.0029^{b}$ & $0.0044 \pm 0.0000^{\mathrm{a}}$ \\
\hline
\end{tabular}

SE-semolina durum; OS—onion skin powder; PAC—-total phenolic acid content; Q-quercetin; $\mathrm{Q}$ 4' G-quercetin $4^{\prime}$-gluciside; $\mathrm{ABTS}^{+}$- radical-scavenging ability against $\mathrm{ABTS}^{+} ; \mathrm{RP}$-reducing power; $\mathrm{CHP}$-chelating power; IC50 - extract concentration ( $\mathrm{mg} \mathrm{DW} / \mathrm{mL}$ ) provided $50 \%$ of activity based on a dose-dependent mode of action. Different letters indicate significant difference $(p<0.05)$.

\subsection{Antioxidant Activity}

Flavonoids and phenolic acids, mostly via radical-scavenging mechanisms, are the most important chemical classes exhibiting antioxidant activity. During dry onion skin formation or storage, the glucosides of quercetin are converted into quercetin. Therefore, the concentration of that compound is the highest in the abaxial epidermis of onion [48]. Quercetin is a strong in vitro antioxidant with the ability to scavenge free radicals and chelate metal ions, and in addition, it possesses anti-inflammatory properties. According to the current state of knowledge, quercetin, as well as organosulfur compounds, are probably responsible for the anti-obesity potential of Allium cepa $[3,49]$. 
The dry skin of onion, which was used in this research as a potential addition to pasta, had high antioxidant activity (Table 1), which was reflected in the properties of fortified pastas (Figure 2). Semolina showed significantly lower antioxidant properties (probably caused by the presence of carotenoids), but as mentioned previously, its main function is to form a network structure of the dough, which significantly affects the quality of the final product. Fu et al. [42] confirmed that fractions from the durum wheat endosperm (i.e., semolina) had the lowest antioxidant activity and phenolic content of all the milling grain fractions.

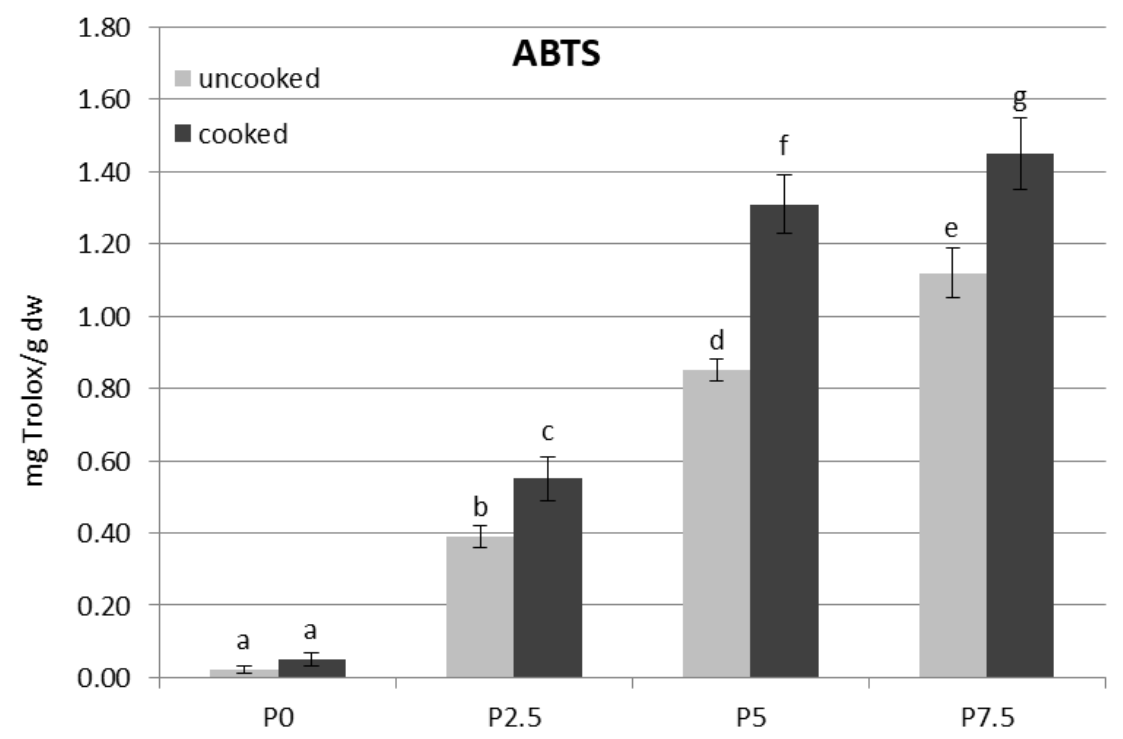

(a)

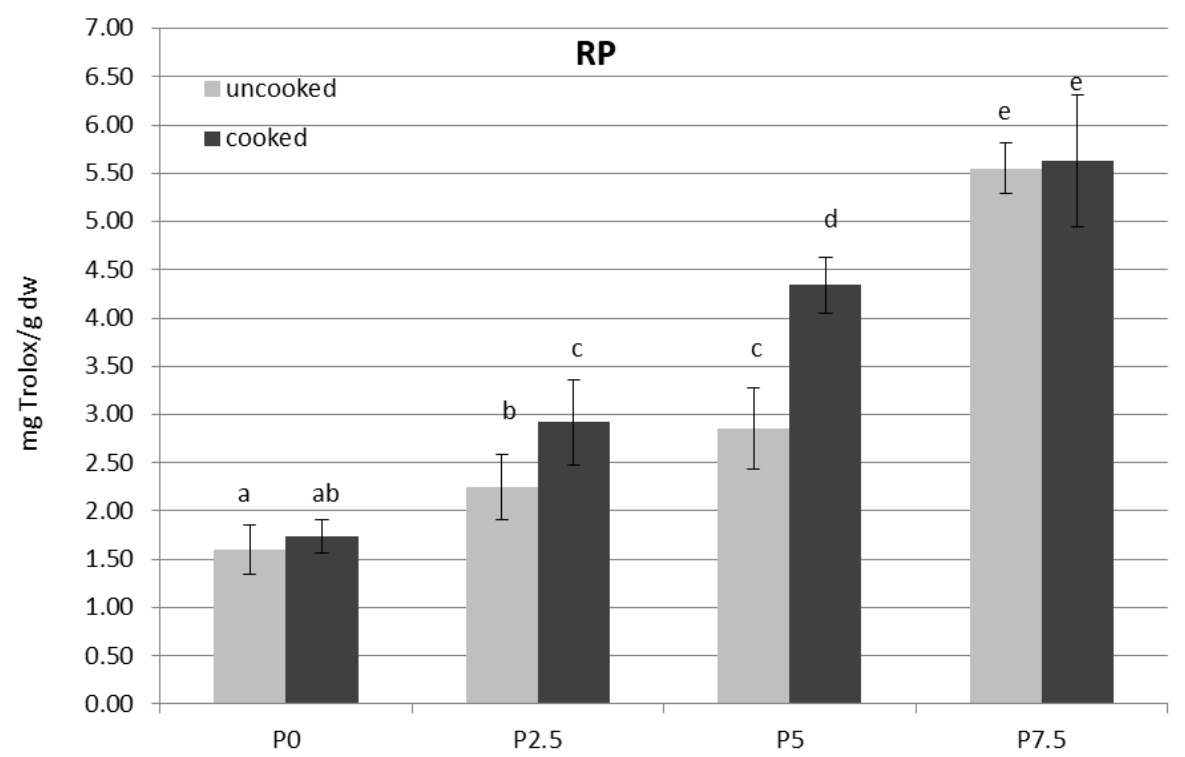

(b)

Figure 2. Cont. 


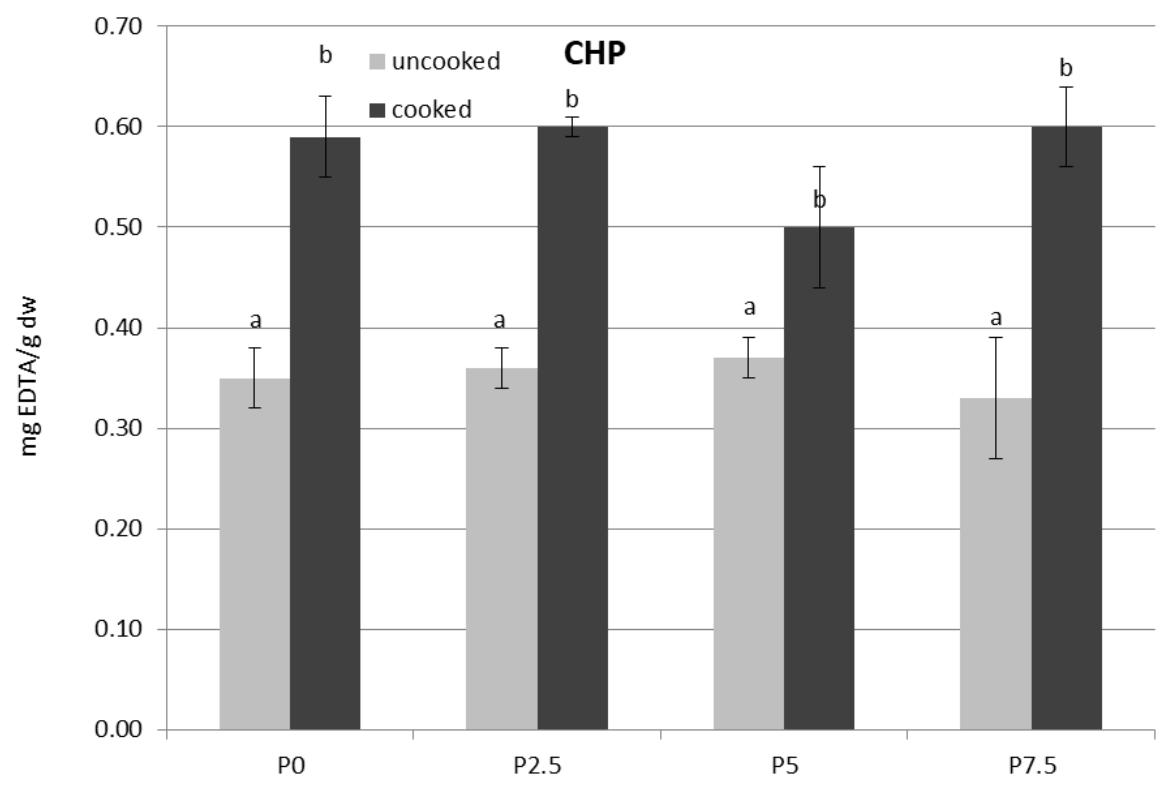

(c)

Figure 2. Antioxidant activity of extracts from uncooked and cooked pastas fortified with onion skin powder. P0— control pasta; P2.5-7.5 pastas fortified with $2.5-7.5 \%(\mathrm{~m} / \mathrm{m})$ of onion skin powder; (a) $\mathrm{ABTS}^{+}$—radical-scavenging ability against $\mathrm{ABTS}^{+*}$; (b) $\mathrm{RP}$-reducing power; (c) $\mathrm{CHP}$ —chelating power. Different letters indicate significant difference $(p<0.05)$.

High phenolic content, like that observed in OS as an ingredient in pasta making, could be responsible for the high antioxidant activity of fortified pastas (Figure 2). As predicted on the basis of $\mathrm{Q}$ and PAC content results, cooking the pasta caused an increase in the antioxidant activity, which has been determined by three complementary methods of analysis (Figure 2). The ABTS free radical scavenging activity was significantly higher in cases of the extracts from all uncooked enriched pastas; however, the highest value of this activity for the P7.5 sample was observed. Additionally, the same observations for samples after cooking should be noted (nearly 30-fold higher ABTS antiradical activity for P7.5 sample in comparison to the cooked control pasta). A slightly stronger improvement of the reducing power (RP) was observed in samples from the fortified pastas (in comparison to the control samples). The ABTS and RP activity of extracts increased with the increase of onion skin concentration; however, the increase in CHP value was statistically not significant.

The antioxidant activities of pastas with onion skin powder was most significantly higher than in the control pastas, both cooked and uncooked (Figure 2). An increase in the antioxidant capacity of bakery products supplemented with onion was confirmed in other studies. Michalak-Majewska et al. [50] and Gawlik-Dziki et al. [19] investigated the effect of addition of powder from different onion cultivars on the quality of rolls and bread. In addition, in other studies concerning pasta enriched with phenolic-abundant plant ingredients, higher antioxidant properties with increased plant concentrations were observed $[16,17,44-46]$.

Because cooking methods can significantly change the bioavailability and bioactivity of phenolic compounds [14,48], studies on pastas after cooking are very important issues while creating new functional pastas. Therefore, we also determined the content and pro-health activity of pastas fortified with onion skin powder after cooking. Some studies suggest that the presence of oxygen, water, and heat treatment during food processing may decrease the level of certain sensitive phenolic antioxidants by its oxidative degradation or by the formation of compounds having pro-oxidant action [43,48,51]. In our study, this effect seems to be marginal, and higher concentrations of phenolic compounds and an increase in antioxidant potential could be explained by several mechanisms. Thus, there are 
reports suggesting that cooking may increase the phenolic content and the antioxidant properties. The proposed mechanisms are connected with disruption of cell wall components, resulting in the release of associated polyphenols. Additionally, heating may be associated with releasing the dietary fiber-bound phenolic compounds with high antioxidant activity [52]. In addition, Melini at al. [53] suggested that pasta cooking may influence the antioxidant potential by influencing the content of phenolic compounds and/or by changing the ratio between free and bond forms of phenolics.

Wheat pasta prepared in this study was supplemented with a thermal stable component (dry onion skin), and the products during preparation were not treated under extreme conditions (minimal processing-phenolic-abundant powdered skin was mixed with wheat paste). Moreover, changes in the structure of existing antioxidants and the formation of new antioxidant compounds may improve the initial antioxidant state of cooked pasta fortified with onion skin. This suggests that processing by heating products containing onion components does not cause a drastic loss in antioxidant value. This is in agreement with previous findings that indicate change in the proportions of compounds responsible for antioxidant properties during thermal processes of onions [15,54]. Antioxidant activity of heated onion is highly correlated with the quercetin 3,4-diglucoside (QDG) to quercetin 4-glucoside (QMG) ratio. It is suggested that the higher the QMG concentration, the higher the antioxidant ability of the tissue. Antioxidant potential of flavanols significantly depends on the structure of the compound (catechol group in the B-ring and the 3-hydroxyl group). Therefore it is suggested that QMG would have a greater antioxidant action than QDG, because in the latter, these two basic functions are blocked, whereas in QMG, the 3-hydroxyl group is not conjugated, and thus it may participate in redox reactions or chelate with metal ions, consequently preventing Fenton-type reactions 54,55]. In the pasta samples analyzed in our study, in addition to the quercetin aglycones, quercetin 4-glucoside (QMG) was also identified (Figure 1c). The presence of this compound has probably contributed to an increase in the antioxidant activity of pasta increasing with the quantity of onion skin.

Cooking pasta enriched with onion skin may improve the initial antioxidant status of that product. During this process can be formed compounds such as Maillard reaction products, which have antioxidant activity [55]. These compounds may be also formed during extrusion and drying of pastas [43]. In addition, data obtained in previous studies [43,46] indicate that boiling the water during cooking could enhance the extraction of bound phenolics from the food matrix, thereby increasing their amount during subsequent chemical extraction and determination. Then, it could explain the results obtained in our study, which showed an increase in antioxidant capacity of cooked pastas, independently of the fortification level.

Perhaps the higher concentration of phenolic compounds determined after cooking pasta was influenced by losses of starch and other soluble dry matter components, which may have occurred during cooking the pasta in water. Our earlier study showed that dry matter losses in pastas fortified with dry onion skin are higher than in the samples without vegetable additive and increase with the growth of that additive (onion skin) [16].

The antioxidant activity of phenolic compounds of onion skin was confirmed by other researchers also in an in vivo model. Some studies have indicated that phenolic compounds of onion such as quercetin can increase the antioxidant potential of the hydrophilic and lipid fractions of rat serum in in vivo studies, but the effect was influenced by the form of quercetin (only aglycone or aglycone with monoglycosides) - in the lipid fraction a positive effect was obtained only after the application of the quercetin aglycone preparation [56]. A similar effect was found in another study, but in this research the best antioxidant effect in the lipophilic fraction of rat serum after using protocatechuic acid preparation from onion skin was observed [57]. The above studies also confirm in vivo the dependence of the antioxidant effect of onion skin polyphenols on the dominant form of these compounds.

\subsection{Anti-Inflammatory Properties}

As shown in Table 1 and Figure 3, all analyzed samples possess anti-inflammatory potential expressed as the ability to inhibit LOX, which is an enzyme involved in the inflammatory process. 
High IC50 values indicate low antioxidant activity. The fortification of pastas with dry onion skin caused significant elevation of the anti-inflammatory potential of the samples (LOX inhibition). A linear relationship between the LOXI activity and the amount of OS added was observed. The highest increase of LOX inhibition by phenolic compounds occurring in extracts was observed in pastas enriched with 5 and $7.5 \%(\mathrm{~m} / \mathrm{m})$ of OS (the IC50 values were 0.25 and $0.19 \mathrm{mg} \mathrm{DW} / \mathrm{mL}$, respectively), with respect to the control (IC50 $=0.33 \mathrm{mg}$ DW/mL). Cooking of pastas significantly increased the anti-inflammatory potential of the extracts. An increase in LOX inhibition was already observed in pasta with the lowest level of added onion skin (the IC50 values were below $0.07 \mathrm{mg} \mathrm{DW} / \mathrm{mL}$, with respect to the control IC50 $=0.13 \mathrm{mg} \mathrm{DW} / \mathrm{mL}$ ) (Figure 3). These qualities of pastas are due to the presence of dry onion skin with high anti-inflammatory potential (Table 1). Numerous studies confirmed that onion is the main source of dietary bioavailable quercetin derivatives with strong anti-inflammatory capacity [49].

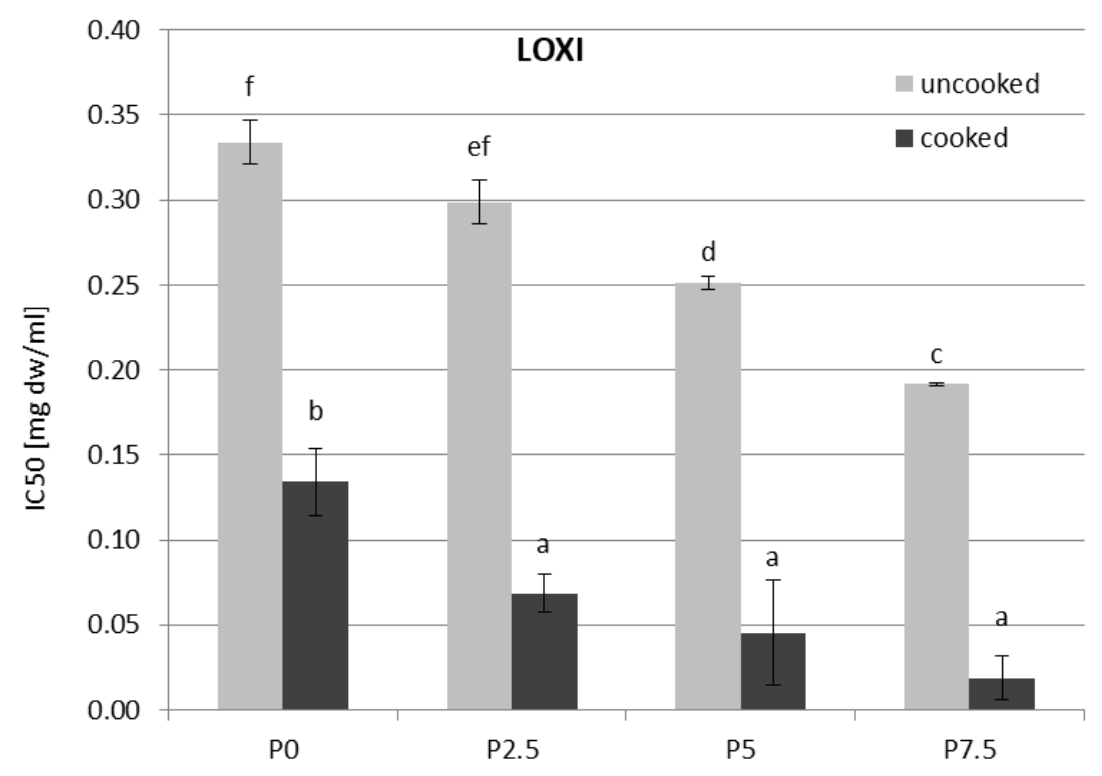

Figure 3. Lipoxygenase inhibitory activity (LOXI) of extracts from uncooked and cooked pastas fortified with onion skin powder. P0—control pasta; P2.5-7.5 pastas fortified with $2.5-7.5 \%(\mathrm{~m} / \mathrm{m})$ of onion skin powder. Different letters indicate significant difference $(p<0.05)$.

Phenolic compounds are a part of the antioxidant system. Their activity depends on chemical structure. They function as free radical scavengers by donating hydrogen or electrons. It has been proven that the antioxidant potential of plant material usually correlates with the phenolic content [42]. The Pearson correlation coefficient between phenolic compounds, analyzed in this research, and ABTS radical scavenging activity of pastas fortified with onion skin powder is very strong $\left(R^{2}=0.930\right.$ and 0.912 for PAC and $Q$, respectively), indicating significant contribution of phenolics to the overall antioxidant capacity of pastas (Table 2). A strong correlation between PAC and RP (0.808), as well as $\mathrm{Q}$ and RP (0.798), was also detected. A moderate correlation was observed for CHP and the analyzed compounds: 0.768 and 0.760 , respectively, for PAC and Q. Similarly, in other research works, the correlation between phenolic content and antioxidant capacity in Allium species was observed [58]. A strong correlation (0.93 and 0.97) between total phenolic compounds and FRAP values was also reported in Allium cepa cultivars [59]. Several authors also observed the strong correlation between total phenolics and antioxidant activity in wheat. Significant correlations between carotenoid content and DPPH scavenging activity in whole grain and the endosperm fraction were reported by Ndolo and Beta [60]. It was also found that yellow pigments in debranned flour are strongly correlated with ABTS scavenging activity [61]. It appears that fortified pastas have valuable health-promoting qualities. 
Table 2. Pearson's correlation coefficients of the phenolic compound (PAC and Q) content and antioxidant and anti-inflammatory activities of pastas fortified with onion skin powder.

\begin{tabular}{ccc}
\hline & PAC & Q \\
\hline ABTS $^{+\cdot}$ & 0.930 & 0.912 \\
RP & 0.808 & 0.798 \\
CHP & 0.768 & 0.760 \\
LOXI & -0.532 & -0.466 \\
\hline
\end{tabular}

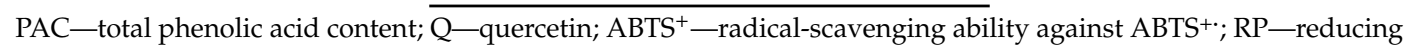
power; $\mathrm{CHP}$-chelating power; LOXI—lipoxygenase inhibitory activity.

The Pearson correlation coefficients ( $\mathrm{r}$ ) showed a negative relationship between the phenol content and the IC50 values concerning LOX inhibition found for the PAC and Q content $(\mathrm{r}=-0.532$; $r=-0.466$, respectively) (Table 2). It is important to note that low IC50 values indicate high potentially anti-inflammatory activity. A moderate relationship, expressed as value of Pearson's correlation coefficients, suggests that apparently, other compounds than those above are responsible for the anti-inflammatory activities of pastas fortified with onion skin powder.

\section{Conclusions}

Onion skin could represent an innovative source of functional ingredients obtained from onion waste, in particular because synthetic additives are being rejected by consumers now. In pastas analyzed in this research, dry onion skin was the source of quercetin and phenolic acids, the concentration of which gradually and significantly increased with the increasing of vegetable component content. Cooking of fortified pastas caused an increase in the content of these pro-health compounds, and their antioxidant and anti-inflammatory potential. Thus, based on the obtained results, it can be concluded that onion skin powder is a valuable material for pasta fortification and could be considered by food technologists. However, studies on the stability and interaction of the constituents of onion by-products with other food ingredients during processing and storage should be conducted.

Author Contributions: Conceptualization, M.M.-M., U.Z., and D.S.; Data curation, M.M.-M., U.Z., and U.S.; Investigation, M.M.-M., U.S., D.S., and M.M.; Methodology, M.M.-M., U.Z., U.S., D.S., and A.S.; Project administration, M.M.-M.; Resources, P.S.; Supervision, M.M.-M.; Visualization, M.M.-M.; Writing—original draft, M.M.-M.; Writing—review and editing, U.Z., U.S., and M.M. All authors have read and agreed to the published version of the manuscript.

Funding: This research received no external funding.

Conflicts of Interest: The authors declare no conflict of interest.

\section{References}

1. FAO. Available online: http://faostat.fao.org/site/567/default.aspx\#ancor (accessed on 2 August 2019).

2. Michalak-Majewska, M.; Czernecki, T.; Radzki, W. Effect of age and gender on consumption of different forms of alliaceous vegetables and their dietary supplements in south-east Europe. Polish J. Commod. Sci. 2015, 3, 50-57.

3. Marrelli, M.; Amodeo, V.; Statti, G.; Conforti, F. Biological properties and bioactive components of Allium cepa L.: Focus on potential benefits in the treatment of obesity and related comorbidities. Molecules 2019, 24, 119. [CrossRef] [PubMed]

4. Shafiq, S.; Shakir, M.; Ali, Q. Medicinal uses of onion (Allium cepa L.): An overview. Life Sci. J. 2017, 14, $100-107$.

5. Bhattacharjee, S.; Sultana, A.; Sazzad, M.H.; Islam, M.A.; Ahtashom, M.M.; Asaduzzaman, M. Analysis of the proximate composition and energy values of two varieties of onion (Allium cepa L.) bulbs of different origin: A comparative study. Int. J. Nutr. Food Sci. 2013, 2, 246-253. [CrossRef]

6. Lee, J.; Mitchell, A.E. Quercetin and isorhamnetin glycosides in onion (Allium cepa L.): Varietal comparison, physical distribution, coproduct evaluation, and long-term storage stability. J. Agric. Food Chem. 2011, 59, 857-863. [CrossRef] 
7. Özcan, M.M.; Süleyman, D.; Uslu, N. Effect of species on total phenol, antioxidant activity and phenolic compounds of different wild onion bulbs. J. Food Meas. Charact. 2018, 12, 902-905. [CrossRef]

8. Sharma, K.; Mahato, N.; Nile, S.H.; Lee, E.T.; Lee, Y.R. Economical and environmentally-friendly approaches for usage of onion (Allium cepa L.) waste. Food Funct. 2016, 7, 3354-3369. [CrossRef]

9. Sindhu, R.; Gnansounou, E.; Rebello, S.; Binod, P.; Varjani, S.; Thakur, I.; Shekhar, N.R.B.; Pandey, A. Conversion of food and kitchen waste to value-added products. J. Environ. Manag. 2019, 241, 619-630. [CrossRef]

10. Benítez, V.; Mollá, E.; Martín-Cabrejas, M.A.; Aguilera, Y.; López-Andréu, F.J.; Cools, K.; Terry, L.A.; Esteban, R.M. Characterization of industrial onion wastes (Allium cepa L.): Dietary fibre and bioactive compounds. Plant. Food Hum. Nutr. 2011, 66, 48-57. [CrossRef]

11. Gawlik-Dziki, U.; Kaszuba, K.; Piwowarczyk, K.; Świeca, M.; Dziki, D.; Czyż, J. Onion skin—raw material for the production of supplement that enhances the health-beneficial properties of wheat bread. Food Res. Inter. 2015, 73, 97-106. [CrossRef]

12. Wiczkowski, W.; Nèmeth, K.; Buciński, A.; Piskuła, M.K. Bioavailability of quercetin from flesh scales and dry skin of onion in rats. Pol. J. Food Nutr. Sci. 2003, 12, 95-99.

13. Wiczkowski, W.; Romaszko, J.; Bucinski, A.; Szawara-Nowak, D.; Honke, J.; Zieliński, H.; Piskuła, M.K. Quercetin from shallots (Allium cepa L. var. aggregatum) is more bioavailable than its glucosides. J. Nutr. 2008, 138, 885-888. [CrossRef] [PubMed]

14. Ahmed, M.; Eun, J.B. Flavonoids in fruits and vegetables after thermal and nonthermal processing: A review. Crit. Rev. Food Sci. Nutr. 2018, 58, 3159-3188. [CrossRef] [PubMed]

15. Nèmeth, K.; Takàcsova, M.; Piskuła, M.K. Effect of cooking on yellow onion quercetin. Pol. J. Food Nutr. Sci. 2003, 12, 170-174.

16. Michalak-Majewska, M.; Teterycz, D.; Muszyński, S.; Radzki, W.; Sykut-Domańska, E. Influence of onion skin powder on nutritional and quality attributes of wheat pasta. PLoS ONE 2020, 15, 0227942. [CrossRef]

17. Sęczyk, Ł.; Świeca, M.; Gawlik-Dziki, U. Nutritional and health-promoting properties of bean paste fortified with onion skin in the light of phenolic-food matrix interactions. Food Funct. 2015, 6, 3560-3566. [CrossRef]

18. Sayed, H.S.; Hassan, N.M.M.; El khalek, M.H.A. The effect of using onion skin powder as a source of dietary fiber and antioxidants on properties of dried and fried noodles. Curr. Sci. Int. 2014, 3, 468-475.

19. Gawlik-Dziki, U.; Świeca, M.; Dziki, D.; Baraniak, B.; Tomiło, J.; Czyż, J. Quality and antioxidant properties of breads enriched with dry onion (Allium cepa L.) skin. Food Chem. 2013, 138, 1621-1628. [CrossRef]

20. Tonyali, B.; Sensoy, I. The effect of onion skin powder addition on extrudate properties. Acta Hortic. 2017, 1152, 393-398. [CrossRef]

21. Mourtzinos, I.; Prodromidis, P.; Grigorakis, S.; Makris, D.P.; Biliaderis, C.G.; Moschakis, T. Natural food colorants derived from onion wastes: Application in a yoghurt product. Electrophoresis 2018, 39, 1975-1983. [CrossRef]

22. Pucciarini, L.; Ianni, F.; Petesse, V.; Pellati, F.; Brighenti, V.; Volpi, C.; Gargaro, M.; Natalini, F.; Clementi, C.; Sardella, R. Onion (Allium cepa L.) skin: A rich resource of biomolecules for the sustainable production of colored biofunctional textiles. Molecules 2019, 24, 634. [CrossRef] [PubMed]

23. Krishnan, M.; Prabhasankar, P. Health based pasta: Redefining the concept of the next generation convenience food. Crit. Rev. Food Sci. Nutr. 2012, 52, 9-20. [CrossRef] [PubMed]

24. Trigo, J.P.; Alexandre, E.M.M.C.; Saraiva, J.A.; Pintado, M.E. High value-added compounds from fruit and vegetable by-products - Characterization, bioactivities, and application in the development of novel food products. Crit. Rev. Food Sci. Nutr. 2019, 11, 1-29. [CrossRef] [PubMed]

25. Jalgaonkar, K.; Jha, S.K.; Mahawar, M.K. Influence of incorporating defatted soy flour, carrot powder, mango peel powder, and moringa leaves powder on quality characteristics of wheat semolina-pearl millet pasta. J. Food Proc. Preserv. 2018, 42, e13575. [CrossRef]

26. Padalino, L.; Conte, A.; Lecce, L.; Likyova, D.; Sicari, V.; Pellicanò, T.M.; Poiana, M.; Del Nobile, M.A. Functional pasta with tomato by-product as a source of antioxidant compounds and dietary fibre. Czech. J. Food Sci. 2017, 35, 48-56.

27. Pasqualone, A.; Punzi, R.; Trani, A.; Summo, C.; Paradiso, V.M.; Caponio, F.; Gambacorta, G. Enrichment of fresh pasta with antioxidant extracts obtained from artichoke canning by-products by ultrasound-assisted technology and quality characterisation of the end product. Int. J. Food Sci. Technol. 2017, 52, 2078-2087. [CrossRef] 
28. Kaur, G.; Sharma, S.; Nagi, H.P.S.; Dar, B.N. Functional properties of pasta enriched with variable cereal brans. J. Food Sci. Technol. 2012, 49, 467-474. [CrossRef]

29. Gallegos-Infante, J.A.; Rocha-Guzman, N.E.; Gonzalez-Laredo, R.F.; Ochoa-Martínez, L.A.; Corzo, N.; Bello-Perez, L.A.; Medina-Torres, L.; Peralta-Alvarez, L.E. Quality of spaghetti pasta containing Mexican common bean flour (Phaseolus vulgaris L.). Food Chem. 2010, 119, 1544-1549. [CrossRef]

30. Padalino, L.; D’Antuono, I.D.; Durante, M.; Conte, A.; Cardinali, A.; Linsalata, V.; Mita, G.; Logrieco, A.F.; Del Nobile, M.A. Use of olive oil industrial by-product for pasta enrichment. Antioxidants 2018, 7, 59. [CrossRef]

31. Liu, T.; Hamid, N.; Kantono, K.; Pereira, L.; Farouk, M.; Knowles, S.O. Effects of meat addition on pasta structure, nutrition and in vitro digestibility. Food Chem. 2016, 213, 108-114. [CrossRef]

32. Lu, X.; Brennan, M.A.; Serventi, L.; Liu, J.; Guan, W.; Brennan, C.S. Addition of mushroom powder to pasta enhances the antioxidant content and modulates the predictive glycaemic response of pasta. Food Chem. 2018, 264, 199-209. [CrossRef] [PubMed]

33. Złotek, U. Antioxidative, potentially anti-inflammatory, and antidiabetic properties, as well as oxidative stability and acceptability, of cakes supplemented with elicited basil. Food Chem. 2018, 243, 168-174. [CrossRef] [PubMed]

34. Szaufer-Hajdrych, M. Phenolic acids in leaves of species of the Aquilegia genus. Herba Polonica 2004, 50, 10-14.

35. Ko, E.Y.; Nile, S.H.; Sharma, K.; Li, G.H.; Park, S.W. Effect of different exposed lights on quercetin and quercetin glucoside content in onion (Allium cepa L.). Saudi J. Biol. Sci. 2015, 22, 398-403. [CrossRef] [PubMed]

36. Re, R.; Pellegrini, N.; Proteggente, A.; Pannala, A.; Yang, M.; Rice-Evans, C. Antioxidant activity applying an improved ABTS radical cation decolorization assay. Free Radic. Biol. Med. 1999, 26, 1231-1237. [CrossRef]

37. Guo, J.T.; Lee, H.L.; Chiang, S.H.; Lin, H.I.; Chang, C.Y. Antioxidant properties of the extracts from different parts of broccoli in Taiwan. J. Food Drug Anal. 2001, 9, 96-101. [CrossRef]

38. Oyaizu, M. Studies on products of browning reaction antioxidative activities of products of browning reaction prepared from glucosamine. Jpn. J. Nutr. 1986, 44, 307-315. [CrossRef]

39. Szymanowska, U.; Jakubczyk, A.; Baraniak, B.; Kur, A. Characterisation of lipoxygenase from pea seeds (Pisum sativum var. Telephone L.). Food Chem. 2009, 116, 906-910. [CrossRef]

40. Galani, J.H.Y.; Patel, J.S.; Patel, N.J.; Talati, J.G. Storage of fruits and vegetables in refrigerator increases their phenolic acids but decreases the total phenolics, anthocyanins and vitamin c with subsequent loss of their antioxidant capacity. Antioxidants 2017, 6, 59. [CrossRef]

41. Fuad, T.; Prabhasankar, P. Role of ingredients in pasta product quality: A review on recent development. Crit. Rev. Food Sci. Nutr. 2010, 50, 787-798. [CrossRef]

42. Fu, B.X.; Chiremba, C.; Pozniak, C.J.; Wang, K.; Nam, S. Total phenolic and yellow pigment contents and antioxidant activities of durum wheat milling fractions. Antioxidants 2017, 6, 78. [CrossRef] [PubMed]

43. Fares, C.; Platani, C.; Baiano, A.; Menga, V. Effect of processing and cooking on phenolic acid profile and antioxidant capacity of durum wheat pasta enriched with debranning fractions of wheat. Food Chem. 2010, 119, 1023-1029. [CrossRef]

44. Rajeswari, G.; Susanna, S.; Prabhasankar, P.; Rao, G.V. Influence of onion powder and its hydrocolloid blends on pasta dough, pasting, microstructure, cooking and sensory characteristics. Food Biosci. 2013, 4, 13-20. [CrossRef]

45. Jambrec, D.; Sakač, M.; Mišan, A.; Mandić, A. Effect of autoclaving and cooking on phenolic compounds in buckwheat-enriched whole wheat tagliatelle. J. Cereal Sci. 2015, 66, 1-9. [CrossRef]

46. Aranibar, C.; Pigni, N.B.; Martinez, M.; Aguirre, A.; Ribotta, P.; Wunderlin, D.; Borneo, R. Utilization of a partially-deoiled chia flour to improve the nutritional and antioxidant properties of wheat pasta. LWT Food Sci. Technol. 2018, 89, 381-387. [CrossRef]

47. Zhu, F.; Li, J. Physicochemical and sensory properties of fresh noodles fortified with ground linseed (Linum usitatissimum). LWT Food Sci. Technol. 2019, 101, 847-853. [CrossRef]

48. Sharma, K.; Ko, E.Y.; Assefa, A.D.; Ha, S.; Nile, S.H.; Lee, E.T.; Park, S.W. Temperature-dependent studies on the total phenolics, flavonoids, antioxidant activities, and sugar content in six onion varieties. J. Food Drug Anal. 2015, 23, 243-252. [CrossRef]

49. Lesjak, M.; Beara, I.; Simin, N.; Pintać, D.; Majkić, T.; Bekvalac, K.; Orčić, D.; Mimica-Dukić, N. Antioxidant and anti-inflammatory activities of quercetin and its derivatives. J. Func. Food. 2018, 40, 68-75. [CrossRef] 
50. Michalak-Majewska, M.; Sołowiej, B.; Sławińska, A. Antioxidant activity, technological and rheological properties of baked rolls containing dried onions (Allium cepa L.). J. Food Proc. Preserv. 2017, 41, e12914. [CrossRef]

51. Borrelli, G.M.; Troccoli, A.; Di Fonzo, N.; Fares, C. Durum wheat lipoxygenase activity and other quality parameters that affect pasta colour. Cereal Chem. 1999, 76, 335-340. [CrossRef]

52. Moyo, S.M.; Mavumengwana, V.; Kayitesi, E. Effects of cooking and drying on phenolic compounds and antioxidant activity of African green leafy vegetables. Food Rev. Int. 2018, 34, 248-264. [CrossRef]

53. Melini, V.; Meliniand, F.; Acquistucci, R. Phenolic Compounds and Bioaccessibility Thereof inFunctional Pasta. Antioxidants 2020, 9, 343. [CrossRef] [PubMed]

54. Makris, D.P.; Rossiter, J.T. Domestic processing of onion bulbs (Allium cepa) and asparagus spears (Asparagus officinalis): Effect on flavonol content and antioxidant status. J. Agric. Food Chem. 2001, 49, 3216-3222. [CrossRef] [PubMed]

55. Hirota, S.; Shimoda, T.; Takahama, U. Tissue and spatial distribution of flavonol and peroxidase in onion bulbs and stability of flavonol glucosides during boiling of the scales. J. Agric. Food Chem. 1998, 46, 3497-3502. [CrossRef]

56. Grzelak-Błaszczyk, K.; Milala, J.; Kosmala, M.; Kołodziejczyk, K.; Sójka, M.; Czarnecki, A.; Klewicki, R.; Juśkiewicz, J.; Fotschki, B.; Jurgoński, A. Onion quercetin monoglycosides alter microbial activity and increase antioxidant capacity. J. Nutr. Biochem. 2018, 56, 81-88. [CrossRef]

57. Grzelak-Błaszczyk, K.; Milala, J.; Kołodziejczyk, K.; Sójka, M.; Czarnecki, A.; Kosmala, M.; Klewicki, R.; Fotschki, B.; Jurgoński, A.; Juśkiewicz, J. Protocatechuic acid and quercetin glucosides in onions attenuate changes induced by high fat diet in rats. Food Funct. 2020, 11, 3585-3597. [CrossRef]

58. Assefa, A.D.; Jeong, Y.J.; Kim, D.J.; Jeon, Y.A.; Lee, J.R.; Ko, H.C.; Baek, H.J.; Sung, J.S. Assessing phenolic content and antioxidant potential diversity in Allium plants using multivariate data analysis. Funct. Hortic. 2018, 59, 759-773. [CrossRef]

59. Kaur, C.; Joshi, S.; Kapoor, H.C. Antioxidants in onion (Allium cepa L) cultivars grown in India. J. Food Biochem. 2009, 33, 184-200. [CrossRef]

60. Ndolo, V.U.; Beta, T. Distribution of carotenoids in endosperm, germ, and aleurone fractions of cereal grain kernels. Food Chem. 2013, 139, 663-671. [CrossRef]

61. Žilić, S.; Serpen, A.; Akillioğlu, G.; Janković, M.; Gökmen, V. Distributions of phenolic compounds, yellow pigments and oxidative enzymes in wheat grains and their relation to antioxidant capacity of bran and debranned flour. J. Cereal Sci. 2012, 56, 652-658. [CrossRef]

Publisher's Note: MDPI stays neutral with regard to jurisdictional claims in published maps and institutional affiliations.

(C) 2020 by the authors. Licensee MDPI, Basel, Switzerland. This article is an open access article distributed under the terms and conditions of the Creative Commons Attribution (CC BY) license (http://creativecommons.org/licenses/by/4.0/). 